\title{
Dispersed Organic Matter Analysis by Fast Soft X-Ray Mapping
}

Colin MacRae ${ }^{1}$, Claudio Delle Paine ${ }^{2}$, Nicholas Wilson ${ }^{3}$, Aaron Torpy ${ }^{3}$, Dave Dewhurst ${ }^{2}$, Cameron Davidson ${ }^{4}$, Kitty Milliken ${ }^{5}$ and Faiz Mohinudeen ${ }^{6}$

${ }^{1}$ CSIRO Mineral Resources, Clayton, Victoria, Australia, ${ }^{2}$ CSIRO Energy, Western Australia, Australia, ${ }^{3} \mathrm{CSIRO}$ Mineral Resources, Clayton, Australia, ${ }^{4}$ CSIRO Mineral Resources, Victoria, Australia, ${ }^{5}$ University of Texas at Austin, Texas, United States, ${ }^{6}$ CSIRO Energy, Queensland, Australia

Hydrocarbon exploration relies upon both the assessment of the thermal maturity of source rocks and their generative potential. The most widely used measure of thermal maturity is the optical vitrinite reflectance technique originally developed for the investigation of coals. This technique utilizes optical microscopy to measure the mean reflectivity of vitrinite macerals in sedimentary organic matter [1]. It has been recently noted that this technique produces variable results depending upon the sample preparation technique [2]. The following study was undertaken to help elucidate the role of sample preparation and determine if fast soft x-ray emission spectroscopy (SXES) at liquid nitrogen temperatures can be used to spectroscopically differentiate the forms of organic material associated with gas and oil deposits. We examined a series of organic-rich samples from the same source rock sampled across different locations within the Beetaloo Basin (Northern Territory, Australia) which have experienced different heating conditions. Specifically, the samples span a range of thermal maturities quantified by conventional reflectance measurements as early oil mature (E2844), oil mature (E2845), and over mature (Tarlee S3). The focus of this study has been to use the $4^{\text {th }}$ order C K reflection collected using a $200 \mathrm{~N}$ grating coupled with a fast CCD camera to measure the soft x-rays, utilizing the quad readout mode which is optimized for fast x-ray throughput [3]. The fast throughput together with the cryogenic temperatures allows soft $\mathrm{x}$-ray measurements to be made before the onset of damage to the carbonaceous samples.

Samples were prepared by mounting in $10 \mathrm{~mm}$ pucks, polishing down to $0.25 \mu \mathrm{m}$ diamond, and ion beam milled as a final polish prior to coating with a $2 \mathrm{~nm}$ Ir metal film. Maps were collected on a JEOL $8530 \mathrm{~F}$ at $7 \mathrm{kV}, 60 \mathrm{nA}$ and between 100-300 ms dwell, the stage was scanned with a step and beam size of $200 \mathrm{~nm}$. Typically, maps were acquired in 1-2 days. Maps longer than 2.5 days were problematic due to ice buildup on the sample surface. Fig. 1 (a) shows the shale of the Tarlee S3 sample contains apatite, quartz, and k-feldspar together with pore-filling by carbonaceous material. The $\mathrm{C} \mathrm{K} 4^{\text {th }}$ order spectrum, Fig. 1 (b), from the carbonaceous material from this map and two others show the changes to the C K peak shape, with the over-mature Tarlee S3 sample moving to lower energy. The E2845 and E2844 show a broader peak structure with the presence of a $\pi$-bonding peak [4]. Hydrocarbons from both these samples have been reported to be amorphous when measured by XRD. The main peak in these samples is centered at $69.6 \mathrm{eV}\left(278.4 \mathrm{eV} \mathrm{C} \mathrm{K} 1^{\text {st }}\right.$ order $)$, which is similar to a peak position and spectral shape observed in polymerized-C60 crystal [5]. In contrast, the Tarlee S3 sample was sourced from a host rock near to a magmatic intrusion which would have heated the surrounding region, likely graphitizing the hydrocarbons. When compared to HOPG, the Tarlee S3 samples show similar spectral features including the presence of both $\pi$ and $\sigma$ bonding (Fig. 2). This study illustrates the ability of SXES to provide new insight into the carbon bonding present within hydrocarbon deposits. 


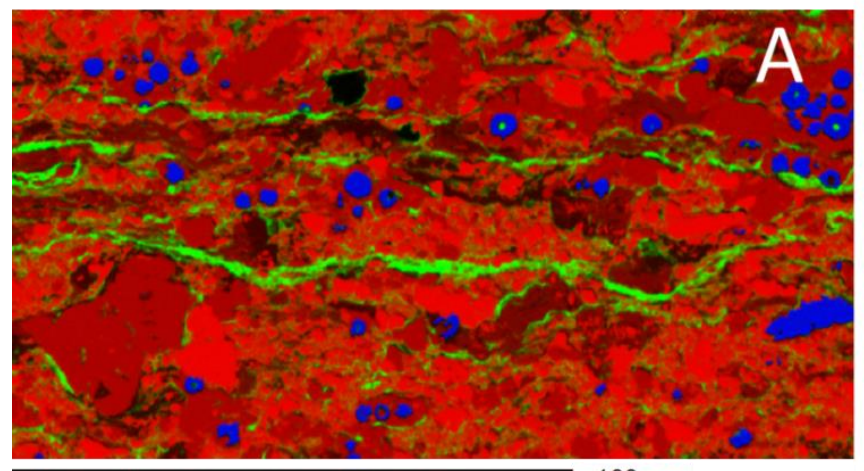

$100 \mu \mathrm{m}$

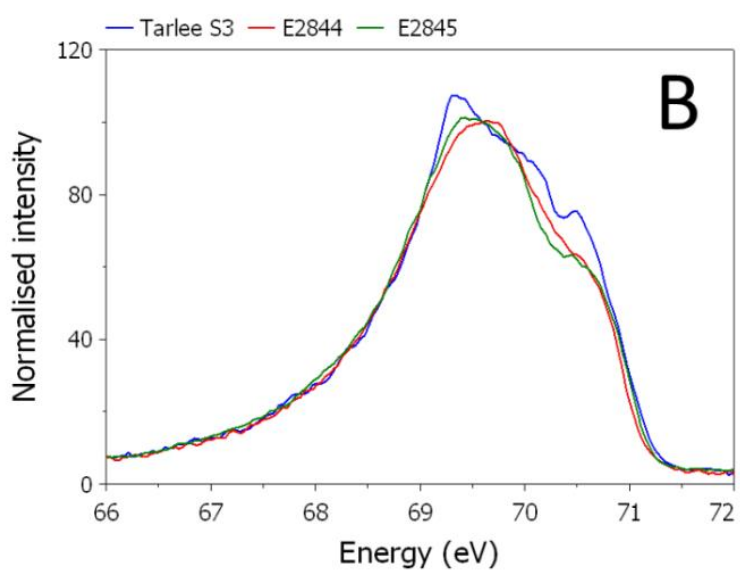

Figure 1. Figure 1. (a) Map of sample Tarlee S3 showing quartz (bright red), k-feldspar (dark red), apatite (blue), and sedimentary organic matter (green) in a source rock sample from the Beetaloo Basin (Northern Territory, Australia), (b) Soft X-ray spectra from the carbonaceous regions of E2845, E2844, and Tarlee S3 show variations in the structure of the $\mathrm{C} \mathrm{K} 4$ th order peak. The $\mathrm{C} \mathrm{K} 4$ th order peak has been smoothed by averaging 2 pixels.

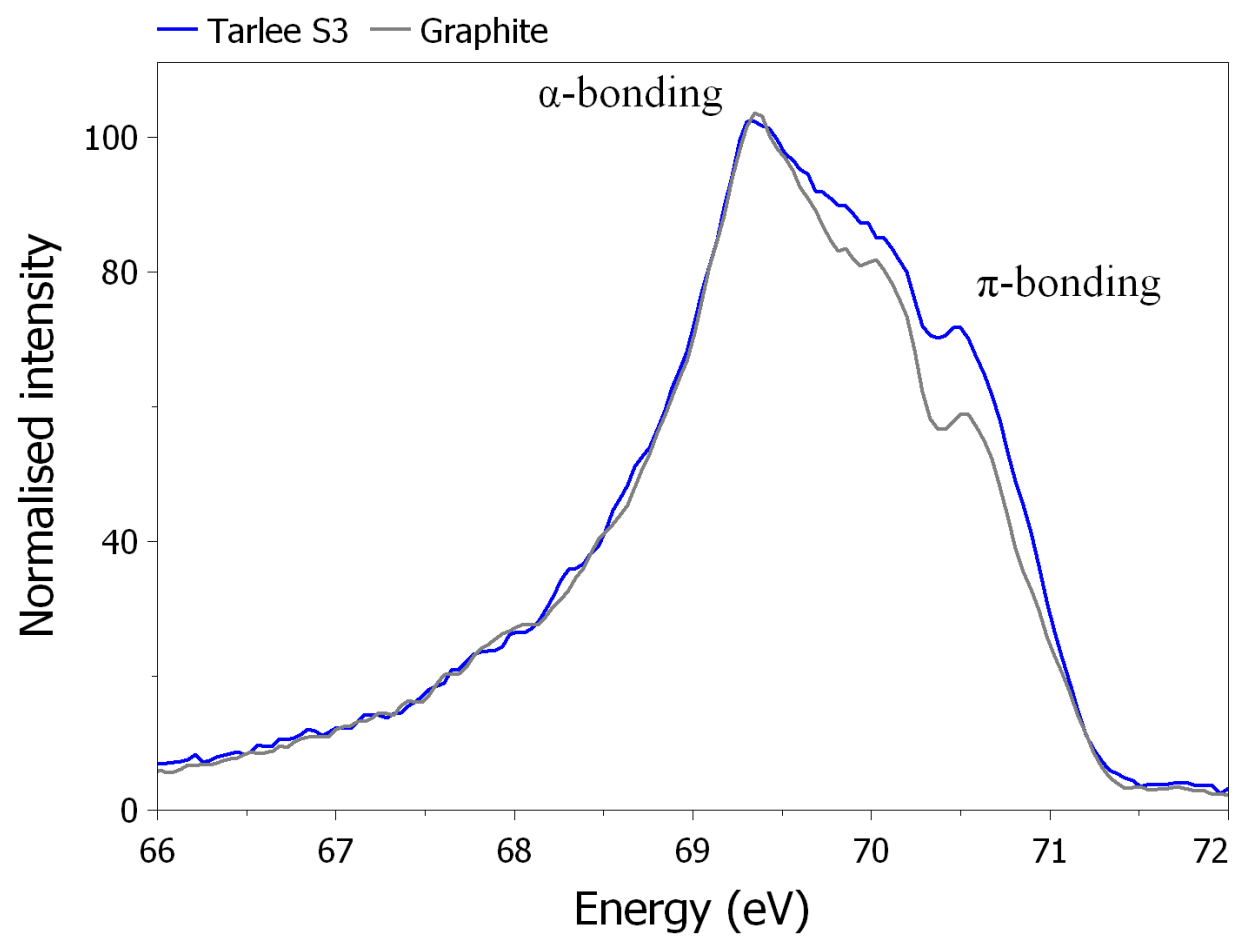

Figure 2. Figure 2. Comparison of $\mathrm{C} \mathrm{K} 4$ th order peak shape from hydrocarbons in a Tarlee S3 sample compared to HOPG (c-axis). Both spectra show $\pi$ and $\sigma$ bonding associated with graphitic structures.

\section{References}

[1] S. Cheshire et al., International Journal of Coal Geology 180 (2017) pp. 29-45

[2] B.J. Valentine et al., International Journal of Coal Geology 201 (2019) pp. 86-101

[3] C.M. MacRae et al., Microscopy and Microanalysis 25 (Suppl 2) 2019 pp. 246-247

[4] K. Nueangnoraj et al., Carbon 62 (2013) pp. 455-464

[5] M. Terauchi et al., Microscopy and Microanalysis 20 (Suppl 3) 2014 pp. 682-683

The authors gratefully acknowledge funding from the ARC LE130100087 